\title{
SERUM LACTATE DEHYDROGENASE LEVEL IN PREGNANCY INDUCED HYPERTENSION AND FETOMATERNAL OUTCOME
}

\author{
Sarmila Prajapati, ${ }^{1}$ Bekha Laxmi Manandhar, ${ }^{2}$ Suvana Maskey, ${ }^{3}$ Jyoti Sharma ${ }^{4}$
}

${ }^{1}$ Department of Obstetrics and Gynaecology, Paropakar Maternity and Women's Hospital, Kathmandu, ${ }^{2}$ Department of Obstetrics and Gynaecology, Universal College of Medical Science, Bhairahawa, ${ }^{3}$ Department of Obstetrics and Gynaecology, Institute of Medicine, Tribhuvan University Teaching Hospital, Kathmandu, ${ }^{4}$ Senior Consultant Gynaecologist at Meridian Health Care Center, Kathmandu, Nepal

\section{ABSTRACT}

Hypertensive disorders complicate $5-10 \%$ of all pregnancies and associated with potentially dangerous maternal and fetal complications. Studies have shown that pre-eclamptic patients with higher levels of lactate dehydrogenase (LDH) are at high risk of developing subsequent complications with poor maternal and fetal outcome. So with the aim to correlate serum LDH level in pregnancy induced hypertension (PIH) with fetomaternal outcome this hospital based observational descriptive study was done at Tribhuvan University Teaching Hospital (TUTH) for the duration of 1 year from 15th May, 2018 to 14th May, 2019. Women with PIH fulfilling inclusion criteria were enrolled in the study. Serum LDH level was measured and severity of $\mathrm{PIH}$, maternal and perinatal outcome were studied according to the levels of LDH. Results were analyzed using SPSS 18 . The incidence of hypertensive disorder in pregnancy was $4.74 \%$ in this study and total 180 cases were enrolled. The mean serum LDH level increased with increase in severity of PIH. Thirty two (17.7\%) cases had maternal complications and hemolysis elevated liver enzymes and low platelet (HELLP) syndrome was most common complication. More than $2 / 3$ rd (62.5\%) of cases with LDH level $>800$ IU/L had complications. The most common perinatal complication was intrauterine growth restriction (IUGR). The perinatal morbidity and mortality were significantly high in patients with PIH with LDH level >800 IU/l. As with the increase in serum LDH level increase in maternal and fetal complications was observed, LDH can be a useful biochemical marker that reflects the severity of PIH.

\section{KEYWORDS}

Pregnancy induced hypertension, Lactate dehydrogenase, Maternal outcome, Perinatal outcome

\section{CORRESPONDING AUTHOR}

Dr. Suvana Maskey

Assistant Professor,

Department of Obstetrics and Gynaecology

Institute of Medicine, Maharajgunj, Kathmandu, Nepal

Email: suvanashrestha@yahoo.com

Orcid No: https://orcid.org/0000-0001-8354-3489

DOI: https://doi.org/10.3126/nmcj.v23i4.42207 


\section{INTRODUCTION}

Pregnancy induced hypertention (PIH) is a multi-system disorder the exact aetiopathogenesis of which is unknown. ${ }^{1}$ Multiple factors have been implicated amongst which endothelial dysfunction is considered to be most important factor resulting in mild to moderate microangiopathy of target organs, leading to increased cell leakiness, hemolysis and cell death, ultimately excessive leakage of lactate dehydrogenase (LDH) in serum. ${ }^{2,3}$ Women with elevated LDH levels have increased severity of PIH as well as increased risk of developing subsequent complications with poor maternal and fetal outcome.-5 Identification of these high risk patients with elevated LDH level, their close monitoring and prompt management may prevent these complications with subsequent decrease in maternal and fetal morbidity and mortality. ${ }^{3}$ So LDH level can be a useful and reliable biochemical marker in pre-eclampsia. Hence this study is done to correlate serum LDH level in PIH with fetomaternal outcome which subsequently might help in predicting degree of severity of the disease, fetomaternal complications and guide timely intervention whenever indicated.

\section{MATERIALS AND METHODS}

This was a hospital based observational type of study conducted over a period of one year from $15^{\text {th }}$ May 2018 to $14^{\text {th }}$ May, 2019 in Department of Obstetrics and Gynecology at Tribhuvan University Teaching Hospital (TUTH), Kathmandu, Nepal. The sampling technique was consecutive purposive sampling technique, so all pregnant women either primi or multigravida with singleton pregnancy with $\mathrm{BP} \geq 140 / 90 \mathrm{mmHg}$ after 20 week POG on two occasions 4 hours apart admitted in labor room were included for this study. Informed consent was taken from all participants. The exclusion criteria were pregnant women with BP $\geq 140 / 90$ $\mathrm{mm} \mathrm{Hg}$ before 20 week POG, PIH women with preexisting liver disease, renal disease, cardiovascular disease and diabetes mellitus, multiple pregnancy, epilepsy, postpartum PIH and pregnancy with fetal anomaly. Urine dipstick was carried out and PIH investigations were sent including serum LDH level. LDH was measured spectrophotometrically as defined by DGKC (German Society of Clinical Chemistry).

PIH patients were subdivided according to severity into four groups; gestational hypertension, mild preeclampsia, severe preeclampsia, eclampsia. The serum LDH level was correlated with severity of PIH, maternal outcome and perinatal outcome.

LDH level was divided into 3 groups; group 1 $<600 \mathrm{IU} / \mathrm{L}$, group $2600-800 \mathrm{IU} / \mathrm{L}$ and group $3>800$ IU/L. Maternal and perinatal outcome in each group were studied and compared. . They were observed till discharge. For neonatal outcome, neonates were observed till 7 days of life or till the day of discharge of mother whichever is earlier. The result obtained from the laboratory and information obtained was recorded in the master chart daily and was expressed in the forms of tables and figures. Computer software SPSS 18 was used for processing and analysis of the data. An inferential statistics, $p$ value was calculated by using ANOVA test for numerical variables and by Chi square/Fisher exact test for categorical variables. P value of $<0.05$ was regarded as statistically significant. The ethical clearance was taken from Institutional Review Committee (IRC) of Institute of Medicine (IOM), TUTH, before starting the study.

\section{RESULTS}

During study period a total of 226 cases of PIH were admitted for delivery, among which only 180 were enrolled for study and remaining 46 cases were excluded. The incidence of hypertensive disorder in pregnancy was $4.74 \%$ of total deliveries. Age ranged from 17 years to 40 years and most of the cases i.e. $72(40 \%)$ belonged to age group of 25-29 years. Sixty percent of the patients were primiparous and remaining was multiparous.

Among 180 PIH cases, 71 (39.44\%) had gestational hypertension, 49 (27.22\%) mild preeclampsia, $41(22.77 \%)$ severe preeclampsia and 19 (10.55\%) had eclampsia. Serum LDH ranged from 230 to $3064 \mathrm{IU} / \mathrm{L}$ and 99 (55\%) had LDH $<600$ IU/L, 48 (26.6\%) had LDH 600-800 IU/L and $33(18.3 \%)$ had LDH $>800$ IU/L. The blood pressure was significantly higher with higher serum LDH levels $(p<0.001)$.

While evaluating severity of PIH according to LDH level severity of PIH increased along with increasing level of $\mathrm{LDH}$ and association between severity of PIH with LDH level was significant $(p<0.001)$ (Table 1). There was significant rise in mean LDH levels with increasing severity of disease from gestational hypertension (536.39 \pm 178.75), mild preeclampsia (626.59 \pm 225.72), severe preeclampsia (699.54 \pm 254.17$)$ to eclampsia $(1270.63 \pm 753.58) \quad(\mathrm{P}<0.001)$. Eclampsia cases were in $5.05 \%$ and $4.16 \%$ of women with $\mathrm{LDH}<600$ and 600-800 IU/L respectively and $36.36 \%$ in women with $\mathrm{LDH}>$ $800 \mathrm{IU} / \mathrm{L}$. The scatter plot in Fig. 1 shows scatter points showing association of systolic and 

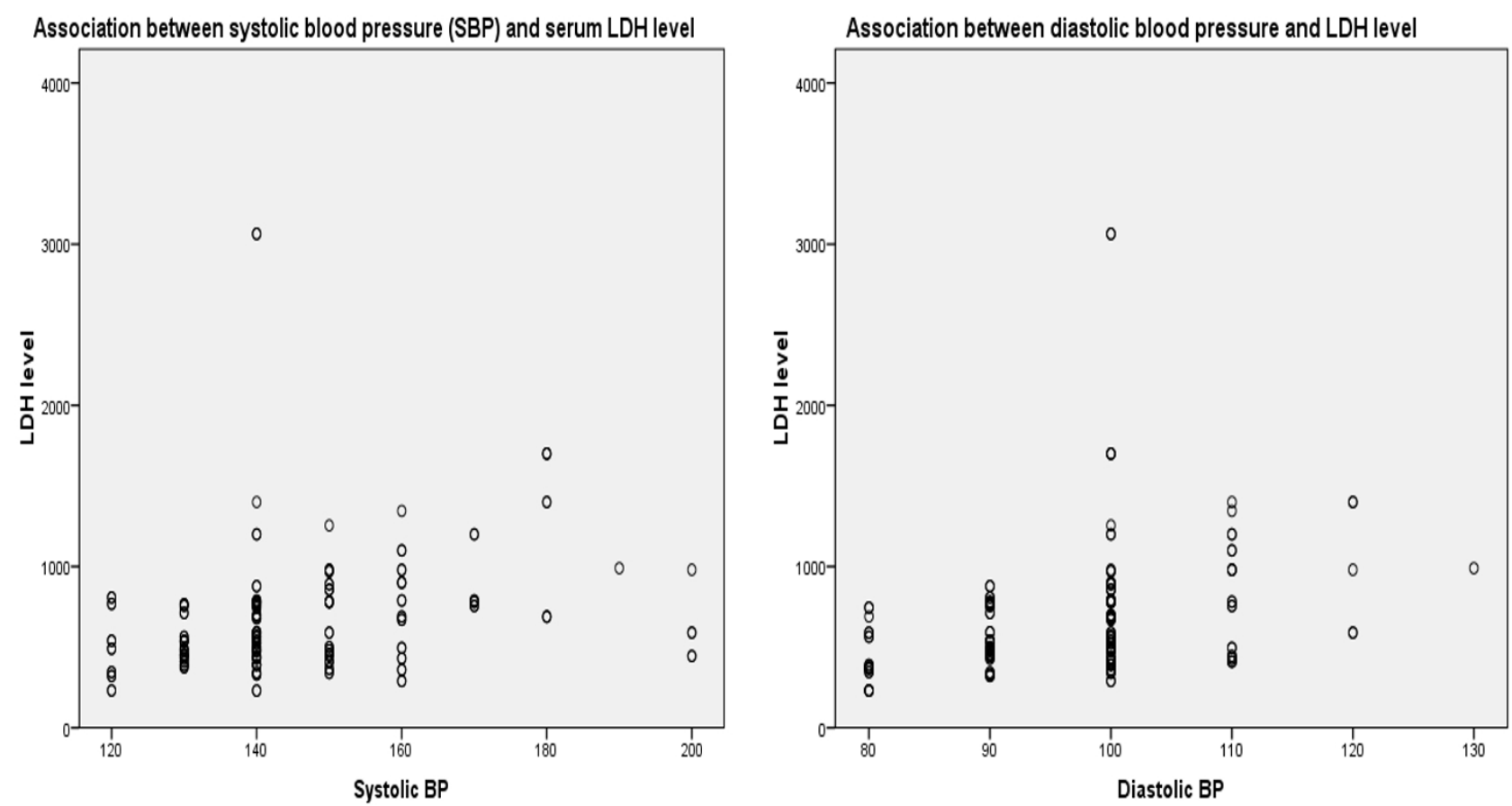

Fig. 1: Association of blood pressure with serum LDH level

\begin{tabular}{|c|c|c|c|c|c|}
\hline \multirow[b]{2}{*}{ Severity PIH } & \multicolumn{5}{|c|}{ Serum lactate dehydrogenase level (IU/L) } \\
\hline & $\begin{array}{c}\text { Group } 1 \\
<600, N=99\end{array}$ & $\begin{array}{c}\text { Group } 2 \\
600-800, N=48\end{array}$ & $\begin{array}{c}\text { Group } 3 \\
>800, N=33\end{array}$ & $\begin{array}{l}\text { Total, } \\
\mathrm{N}=180\end{array}$ & $\begin{array}{c}\mathbf{P} \\
\text { value }\end{array}$ \\
\hline $\begin{array}{l}\text { Gestational } \\
\text { Hypertension }\end{array}$ & $53(53.53 \%)$ & $14(29.16 \%)$ & $4(12.12 \%)$ & $71(39.44 \%)$ & \\
\hline Mild preeclampsia & $25(25.25 \%)$ & $18(37.5 \%)$ & $6(18.18 \%)$ & $49(27.2 \%)$ & \\
\hline Severe preeclampsia & $16(16.16 \%)$ & $14(29.16 \%)$ & $11(33.33 \%)$ & $41(22.77 \%)$ & $<0.001$ \\
\hline Eclampsia & $5(5.05 \%)$ & $2(4.16 \%)$ & $12(36.3 \%)$ & 19 (10.5\%) & \\
\hline Total & 99 (100\%) & $48(100 \%)$ & $33(100 \%)$ & $180(100 \%)$ & \\
\hline
\end{tabular}

*Fisher's exact test

diastolic blood pressure with serum LDH level .

In the present study, caesarean deliveries (52.2\%) were higher than vaginal deliveries (47.77\%). There was more caesarean sections in patients with $\mathrm{LDH}<600 \mathrm{IU} / \mathrm{l}$ and between 600 800IU/l however vaginal deliveries were more in patients with LDH $>800 \mathrm{IU} / \mathrm{L}$ and it was not statistically significant.

Thirty two cases (17.7\%) had complications among which most common complication was HELLP syndrome followed by eclampsia, abruption placenta, acute renal failure, pulmonary edema and postpartum haemorrhage. More than $2 / 3^{\text {rd }}(62.5 \%)$ of cases with $\mathrm{LDH}$ level $>800 \mathrm{IU} / \mathrm{L}$ had complications $(p<0.001)$. Only one maternal death $(3.03 \%)$ was observed during the study period which was in women with LDH levels $>800$ IU/l. Ten (5.55\%) needed ICU admission out of these 8 cases had LDH >800 IU/L, 2 cases had LDH 600$800 \mathrm{IU} / \mathrm{L}$ and none got admitted with $\mathrm{LDH}<600$ IU/L $(\mathrm{p}<0.001)$ (Table 2).

Majority of PIH cases (46.6\%) were in gestational age of 37-39 weeks at the time of delivery. There was significant association between serum LDH 
Table 2: Maternal complications according to LDH level

\begin{tabular}{lccccc|} 
Maternal & \multicolumn{5}{c}{ Serum lactate dehydrogenase level (IU/L) } \\
Complications & $<600, \mathrm{~N}=99$ & $600-800, \mathrm{~N}=48$ & $>800, \mathrm{~N}=33$ & Total, N=180 & P value \\
Yes & $8(25 \%)$ & $4(12.5 \%)$ & $20(62.5 \%)$ & $32(17.7 \%)$ & $<0.001$ \\
HELLP syndrome & $2(2.02 \%)$ & $4(8.33 \%)$ & $16(48.48 \%)$ & $22(12.22 \%)$ & $<0.001$ \\
Eclampsia & $5(5.05 \%)$ & $2(4.1 \%)$ & $12(36.3 \%)$ & $19(10.55 \%)$ & $<0.001$ \\
Abruptio placentae & $2(2.02 \%)$ & $2(4.1 \%)$ & $4(12.12 \%)$ & $8(4.44 \%)$ & 0.046 \\
$\begin{array}{l}\text { Acute Renal failure } \\
\text { DIC (Disseminated }\end{array}$ & $0(0.0 \%)$ & $4(8.33 \%)$ & $3(9.09 \%)$ & $7(3.88 \%)$ & 0.043 \\
$\begin{array}{l}\text { Intravascular } \\
\text { Coagulation) }\end{array}$ & $0(0.0 \%)$ & $1(2.08 \% 0$ & $2(6.06 \%)$ & $3(1.66 \%)$ & 0.051 \\
$\begin{array}{l}\text { Pulmonary edema } \\
\text { Postpartum }\end{array}$ & $0(0.0 \%)$ & $2(4.1 \%)$ & $0(0.0 \%)$ & $2(1.11 \%)$ & 0.103 \\
hemorrhage (PPH) & $0(0.0 \%)$ & $0(0.0 \%)$ & $1(3.03 \%)$ & $1(0.55 \%)$ & 0.183 \\
Maternal death & $0(0.0 \%)$ & $0(0.0 \%)$ & $1(3.03 \%)$ & $1(0.55 \%)$ & 0.183 \\
$\begin{array}{l}\text { Maternal ICU } \\
\text { admission }\end{array}$ & $0(0.0 \%)$ & $2(4.16 \%)$ & $8(24.24 \%)$ & $10(5.55 \%)$ & $<0.001$ \\
\hline
\end{tabular}

level and mean gestation age at the time of delivery as the LDH level increased successively with the decrease in mean gestational age $(p=0.003)$. The mean birth-weight also decreased with the increase in LDH level however it was not statistically significant. The Apgar score at 5 minutes $<6$ was seen in 5 cases and there was no significant relation between it and serum LDH level (Table 3).
Regarding perinatal complications 47 (26.11\%) had IUGR and 14 (7.77\%) had IUFD (Table 4). Among those having LDH level $>800 \mathrm{IU} / \mathrm{L}, 14$ $(42.42 \%)$ had IUGR $(p=0.014)$ and $7(21.21 \%)$ had IUFD $(p=0.009)$. Neonatal death (NND) occurred in 4 cases (2.2\%), out of these, 3 cases had LDH > $800 \mathrm{IU} / \mathrm{L}(\mathrm{p}=0.03)$. Hence perinatal complications such as IUGR, IUFD and NND were significantly associated with raised LDH level.

Table 3: Mean Gestational age at the time of delivery, mean birth weight and Apgar score $<6$ in 5 minutes according to LDH level

Perinatal
outcome Serum lactate dehydrogenase (IU/L)

$<600, \mathrm{~N}=99 \quad 600-800, \mathrm{~N}=48 \quad>800, \mathrm{~N}=33 \quad$ Total, $\mathrm{N}=180 \quad$ P value

Mean gestational

age (weeks)

at the time of

$37.41 \pm 2.58$

$36.47 \pm 3.22$

$35.44 \pm 3.43$

$36.43 \pm 4.28$

0.003

delivery

Mean

birthweight(kg)

$2.59 \pm 0.75$

$2.33 \pm 0.85$

$2.32 \pm 0.97$

$2.47 \pm 0.83$

0.107

Apgar score $<6$

in 5 minutes

2

2

1

5

0.54 
Table 4: Perinatal complications according to LDH level

\begin{tabular}{|c|c|c|c|c|c|}
\hline $\begin{array}{l}\text { Perinatal } \\
\text { outcomes }\end{array}$ & & Serum lacta & dehydrogen & (IU/L) & \\
\hline & $<600, \mathrm{~N}=99$ & $600-800, N=48$ & $>800, N=33$ & Total, N=180 & $P$ value \\
\hline IUGR & $18(18.18 \%)$ & $15(31.25 \%)$ & $14(42.42 \%)$ & 47 (26.11\%) & 0.014 \\
\hline IUFD & $4(4.04 \%)$ & $3(6.25 \%)$ & 7 (21.21\%) & $14(7.77 \%)$ & 0.009 \\
\hline Stillbirth & $1(1.01 \%)$ & 0 & $1(3.03 \%)$ & $2(1.1 \%)$ & 0.50 \\
\hline NNU admission & $15(15.15 \%)$ & $8(16.66 \%)$ & $5(15.15 \%)$ & $28(15.55 \%)$ & 0.96 \\
\hline NICU admission & $1(1.01 \%)$ & $3(6.25 \%)$ & $1(3.03 \%)$ & $5(2.77 \%)$ & 0.10 \\
\hline NND & 0 & $1(2.08 \%)$ & $3(9.09 \%)$ & $4(2.2 \%)$ & 0.03 \\
\hline
\end{tabular}

${ }^{*}$ Chi-square test and Fisher's exact test

\section{DISCUSSION}

Pregnancy induced hypertension is a multisystem disorder which complicates 5-10 \% of all pregnancies. ${ }^{1}$ It can progress to its severe form resulting in life threatening complications to the mother as well as fetus if timely interventions are not taken. In the present study, the incidence of hypertensive disorders in pregnancy including gestational hypertension, preeclampsia, eclampsia, chronic hypertension and chronic hypertension with superimposed preeclampsia was found to be $4.74 \%$ of total deliveries. The most common age group belonged to 25-29 years of age which accounts $40 \%$ of study subjects, findings consistent to the study done by Kant et al. ${ }^{6}$ The impact of parity on preeclampsia is well established as it is primarily a disorder of first pregnancies. ${ }^{7,8}$ In this study also majority of the patients i.e. $108(60 \%)$ were primiparous similar to other studies. ${ }^{3,9,10}$

Among 180 patients enrolled, those patients with severely increased systolic and diastolic BP had higher LDH levels which was also observed by Jaiswar et al ${ }^{11}$ and Mary et al. ${ }^{12}$ Thirty three (18.3\%) women were having LDH >800IU/L, out of which, 12 (36.36\%) were eclampsia, 11(33.33\%) severe preeclampsia, 6 (18.18\%) mild preeclampsia and $4(12.12 \%)$ gestational hypertension $(\mathrm{p}<0.001)$. There was a significant rise in the LDH levels with increasing severity of the PIH $(\mathrm{P}<0.001)$, which was also reported by other studies. ${ }^{13,14}$

Bhave et $a l^{14}$ documented that majority of women with complications had LDH level $>800 \mathrm{IU} / \mathrm{L}$. In the present study also maternal complications were seen in $32(17.7 \%)$ cases among which majority (62.5\%) had LDH level $>800 \mathrm{IU} / \mathrm{L}$. Ten cases needed maternal ICU stay, among which 8 (80\%) had LDH level >800 IU/L. There was one maternal mortality in the present study who had LDH level 3064 IU/L. Hence in this study increase in serum LDH levels were associated with poor maternal outcome in terms of complications, ICU stay and mortality which was statistically significant $(P<0.001)$. Jaiswar SP et $a l^{11}$ also concluded significant increase in maternal morbidity and mortality with increasing serum LDH levels.

In the present study, caesarean deliveries were higher than vaginal deliveries. With the successive decrease in mean gestational age there was increase in level of LDH ( $p=0.003$ ) which was also observed by Andrews et al. ${ }^{13}$ In addition, the present study showed higher level of LDH with the reduction in the average birth weight of babies however it was not statistically significant. Higher level of LDH predict fetal worse outcome in terms of IUGR, IUFD and neonatal death $(p<0.05$, statistically significant) as observed in present and other studies as well. ${ }^{13,14}$ Majority (80\%) of lower Apgar score were found in $\mathrm{LDH}<800 \mathrm{IU} / \mathrm{L}$ hence there was no significant association between Apgar score and increased LDH level $(p=0.547)$. It was consistent with the study done by Gupta et al. ${ }^{15}$ This study also showed no relation between NNU and NICU admission and serum LDH level however there were 5 neonatal mortality $(2.77 \%)$, among these cases $3(75 \%)$ had LDH level $>800$ IU/L finding similar to other studies. ${ }^{3,16}$

This study demonstrated that higher level of LDH was observed with increased severity of PIH like eclampsia and with maternal complications like HELLP syndrome, eclampsia, abruption placentae, acute renal failure which was statistically significant. This study also showed that perinatal complications like IUGR, 
IUFD and neonatal death were more common in PIH cases with LDH level>800 IU/L. Thus, increase in serum LDH level was correlated with severity of PIH and maternal and fetal complications.

\section{Conflict of Interest: None}

\section{Source of Research Fund: None}

\section{REFERENCES}

1. Cunningham $\mathrm{F}$, Leveno $\mathrm{K}$, Bloom $\mathrm{S}$ et al. Hypertensive disorders. Williams obstetrics 2014; 24: 728-9.

2. WHO. Trend in maternal mortality: 1990 to 2010: WHO, UNICEF, UNFPA and The World Bank estimates. 2012.

3. Qublan HS, Ammarin V, Bataineh O et al. Lactic dehydrogenase as a biochemical marker of adverse pregnancy outcome in severe preeclampsia. Med Sci Monit 2005; 11:CR393-7.

4. Singh P, Gaikwad HS, Marwah S, Mittal P, Kaur C. Role of Serum Lactate Dehydrogenase in Pregnancy Induced Hypertension with its Adverse Feto-Maternal Outcome-A Case-control Study. J Clin Diagn Resc 2018; 12(5).

5. Purnima Dey S, Jonal S. Evaluation of serum LDH and gamma glutamyl transferase in preeclamptic pregnancy in third trimester. Int'l J Res Med Sci 2013; 1: 365-8.

6. Kant RH, Mir N, Sarwar S, Gupta S, Najeeb R. Role of maternal serum lactate dehydrogenase as a biochemical marker in pre-eclampsia. IOSR J Dent Med Sci 2015; 14: 12-9.

7. Report of the National High Blood Pressure Education Program Working Group on High Blood Pressure in Pregnancy. Am J Obstet Gynecol 2000; 183: S1-S22.

8. Asgharnia M, Faraji R, Mirhaghjoo N, Roshan ZA, Ashrafkhani B, Moslehi M. Survey of predictive value of 4-hour urine collection for diagnosis of proteinuria in preeclampsia. Iranian J Reprod Med 2013; 11: 647.
9. Roberts CL, Ford JB, Algert CS et al. Populationbased trends in pregnancy hypertension and pre-eclampsia: an international comparative study. Brit Med J Open 2011; 1(1).

10. SR. KR. Significance of lactate dehydrogenase in prediction of pregnancy induced hypertension and it complications. Int'l J Med Res 2016; 4: 1946-52.

11. Jaiswar SP AG, Rekha S, Natu SN, Mohan S. Lactic Dehydrogenase: A Biochemical Marker for Preeclampsia-Eclampsia. J Obstetr Gynecol India 2011; 61: 645-8.

12. Mary VP, Chellatamizh M, Padmanaban S. Role of serum LDH in preeclampsia as a prognostic factor-a cross sectional case control study in tertiary care hospital. Int'l J Reprod Contra Obstetr Gynecol 2017; 6: 596.

13. Andrews L, Patel N. Correlation of serum lactate dehydrogenase and pregnancy induced hypertension with its adverse outcomes. Int'l J Res Med Sci 2016; 4: 1347-50.

14. Bhave NV, Shah PK. A correlation of lactate dehydrogenase enzyme levels in pregnancy induced hypertensive disorders with severity of disease, maternal and perinatal outcomes. Int'l J Reprod Contra Obstetr Gynecol 2017; 6: 4302-8.

15. Gupte S, Wagh G. Preeclampsia-eclampsia. J Obstet Gynaecol India 2014; 64: 4-13.

16. Sreelatha S BA, Ramya S, Sharau S. Estimation of serum LDH and uric acid in preeclampsia and its correlation with maternal and perinatal outcome. Int'l J Adv Computer Res 2015; 2: 447-9. 